\title{
The Vagabond Fluorine Atom: Dissociative Photoionization of trans-1,3,3,3-
}

Tetrafluoropropene

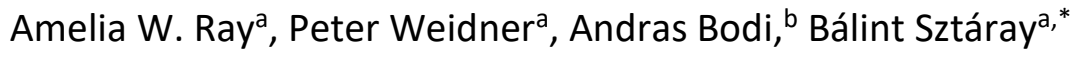

${ }^{a}$ Department of Chemistry, University of the Pacific, Stockton, CA 95211, USA

${ }^{b}$ Laboratory for Synchrotron Radiation and Femtochemistry, Paul Scherrer Institute, CH-5232

Villigen PSI, Switzerland

*Corresponding author: bsztaray@pacific.edu.

\section{List of Schemes:}

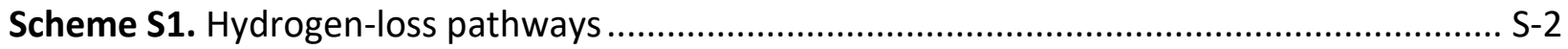

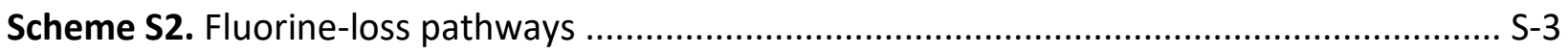

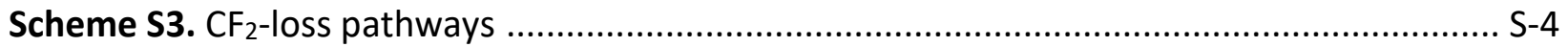


Scheme S1. Hydrogen-loss pathways. All energies are $0 \mathrm{~K}$ values calculated at the $\mathrm{G} 4$ level of theory (except where otherwise stated), reported relative to neutral trans-1,3,3,3tetrafluoropropene.
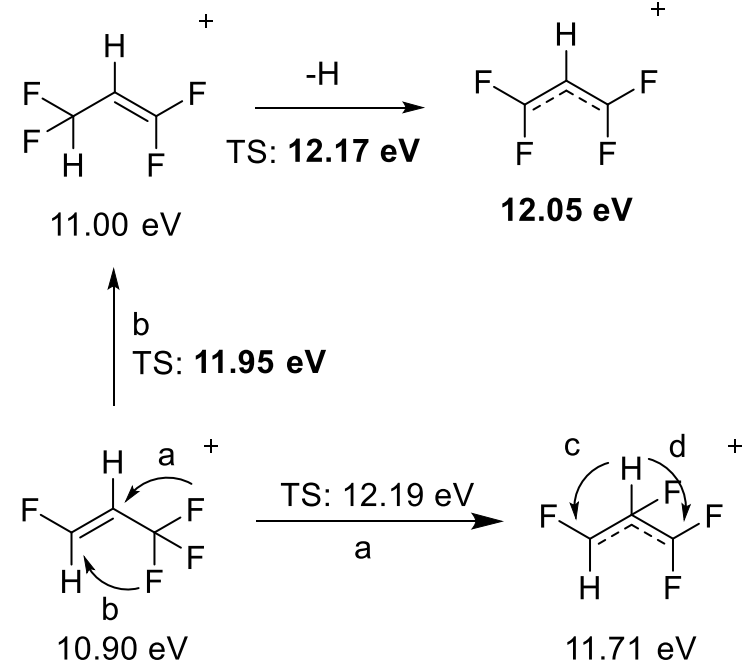

TS: $12.55 \mathrm{eV}$
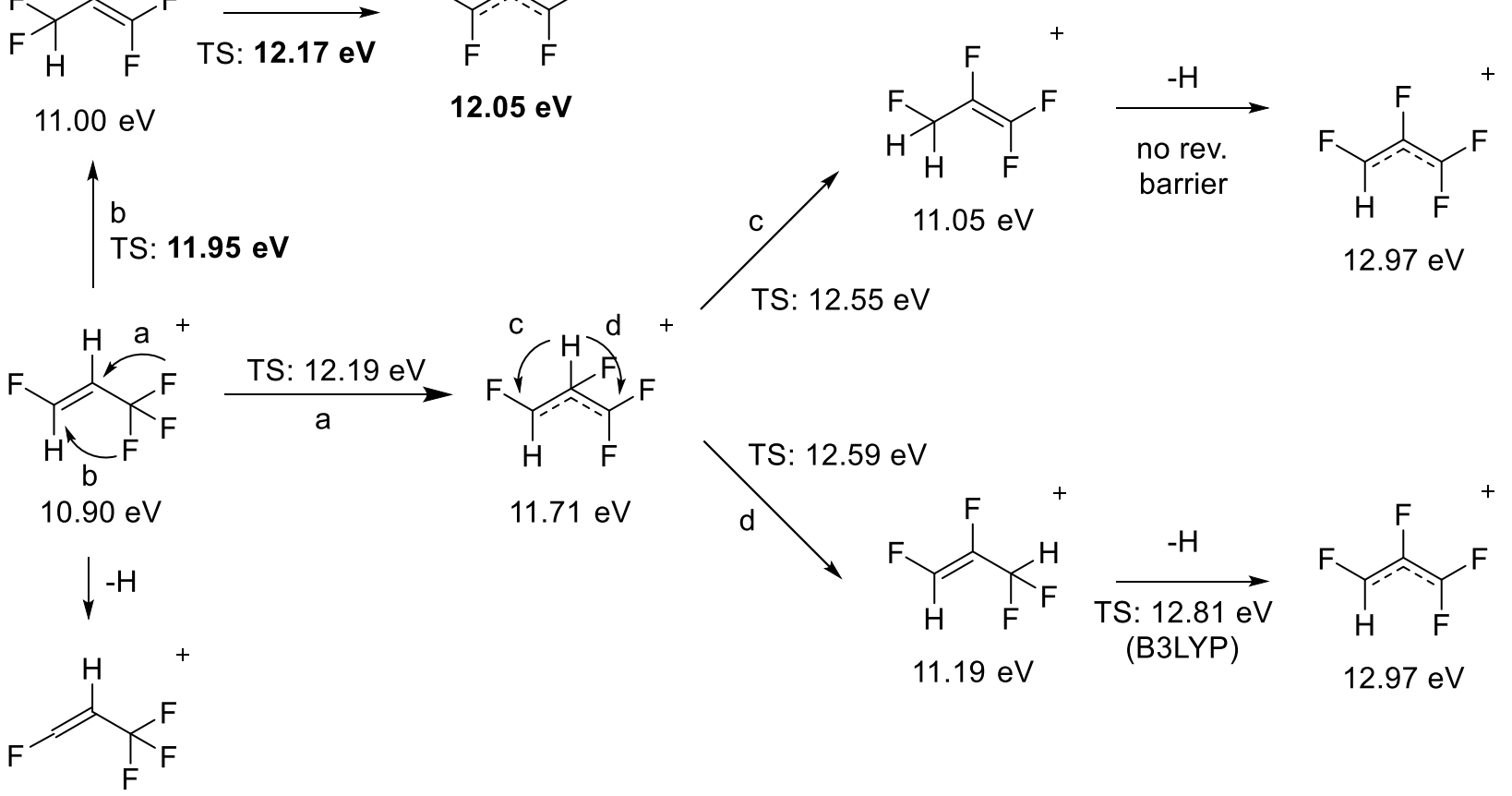

14. $38 \mathrm{eV}$ 
Scheme S2. Fluorine-loss pathways. All energies are $0 \mathrm{~K}$ values calculated at the $\mathrm{G} 4$ level of theory (except where otherwise stated), reported relative to neutral trans-1,3,3,3tetrafluoropropene.

Direct F-Ioss<smiles>O=[W]O[Na]</smiles>

Indirect F-loss

c

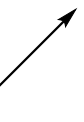

TS: $12.55 \mathrm{eV}$<smiles>[CH2-]CC(/C=C\F)C(F)(F)F</smiles>

$10.90 \mathrm{eV}$<smiles>CC(C=C(F)F)C(F)F</smiles>

$11.00 \mathrm{eV}$

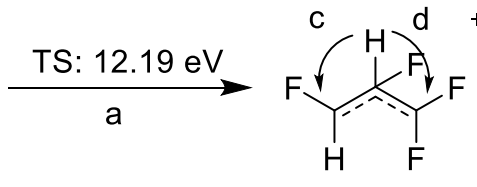

$11.71 \mathrm{eV}$

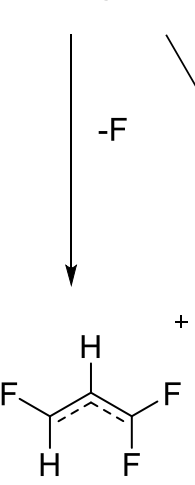

$12.74 \mathrm{eV}$
TS: $12.59 \mathrm{eV}$

d)<smiles>FC(F)=C(F)F</smiles>

$11.05 \mathrm{eV}$

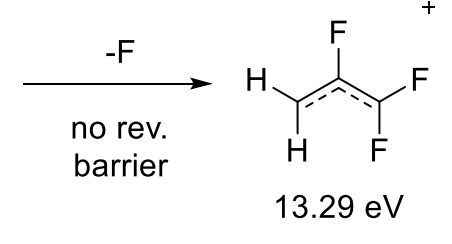

barrier

$13.29 \mathrm{eV}$<smiles>FC=C(F)C(F)F</smiles>

$11.19 \mathrm{eV}$

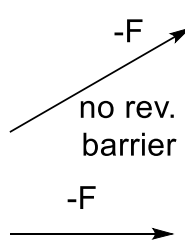<smiles>FC=C(F)F</smiles>

$13.57 \mathrm{eV}$<smiles>FC=C(F)F</smiles>

$13.67 \mathrm{eV}$

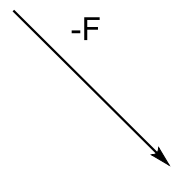

$13.75 \mathrm{eV}$ 
Scheme $\mathbf{S 3}$. $\mathrm{CF}_{2}$-loss pathways. All energies are $0 \mathrm{~K}$ values calculated the $\mathrm{G} 4$ level of theory (except where otherwise stated), reported relative to neutral trans-1,3,3,3-tetrafluoropropene.

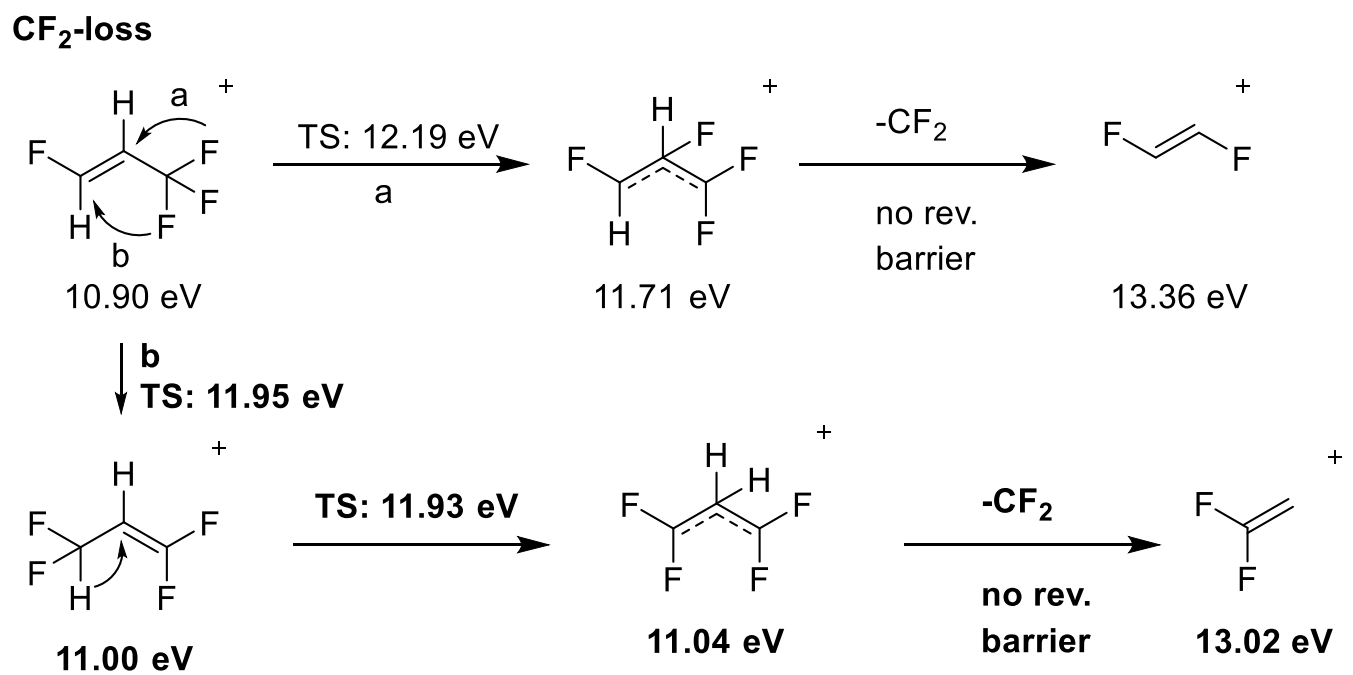

